\title{
Stage and Screen Experience: The Actor's Challenge
}

\author{
Ovunda Ihunwo, Sam Dede
}

\begin{abstract}
Oftentimes, one encounters a silent argument between the stage actor and stars produced as a result of having played either lead or supporting roles in the movies. This has in most cases raised questions as to who is a celebrity between the two. Of more importance is the fact that most celebrities who are screen actors are not trained theatre artists, thereby querying the essence of studying theatre arts when they can actually become headliners without going to an acting school. Consequently therefore, trained actors who derive artistic fulfillment in showing their prowess on stage have become unsung heroes while the society has always celebrated the screen personalities. The reasons are not far-fetched; this is as a result of ignorance both on the side of the society and the actors on both media in the sense that they have failed to realize the challenges that actors are confronted with. This paper shall therefore bring to the fore, principal challenges that confront the actor on both sides and the need to appreciate stage actors as well as those on screen.
\end{abstract}

\section{Introduction}

If you walk into an acting class in the theatre and try to find out exactly why the students have chosen to be trained as actors, not a few will quickly tell you that they look forward to becoming film stars. Try to find out who their mentors are and you will hear names like Genevieve Nnaji, Mercy Johnson, Patience Ozokwor, Olu Jacobs, Ramsey Nouah, Richard Mofe-Damijo, Nkem Owoh, just to mention a few. Their reason is not unconnected with the fact that these are shining stars and celebrities because of their appearance in many Nigerian Video Film blockbusters. Many of these students are not ready to accept the fact that as Hollywood exists, so does Broadway. A few students of acting who probably would have preferred the artistic fulfillment from acting on stage are also discouraged by the fact that these productions seldom come by and can hardly pay their bills even when they do. As a result, most theatre trained actors migrate to the screen and join in the quest for stardom.

From the foregoing, it is imperative to note that theatre schools in Nigeria offer acting courses and training designed for the stage, a system that has made most of these students become stagy on a film set. What is therefore vital today should be the ability of an actor to appreciate where his talents lie, and to assess which medium ultimately offers the best opportunity to shine.

\section{Acting: The Art}

In the preface to his book, Tom Isbell quotes Barrymore's definition of acting as the "art of saying a thing on the stage as if you believed every word you utter to be true as the eternal verities of life." He sees acting as the art of doing a thing on stage as if the logic of the event demanded that precise act and no other. Going by this definition which I think is apt within the context of this paper, acting is therefore the art of telling a truthful lie.

From the definition above, we see that both the stage and screen actor are faced with a common challenge which is the ability to be convincing and believable enough to attract acceptance from members of the audience. To corroborate this statement, Caltagirone posits that "acting in a film or in a dramatic television production is quite different from acting on stage. And at the same time, there are a lot of similarities in the two forms" (275). Several scholars and actor trainers have posited different views on acting styles but have reechoed the need for a truthful pursuit of a character's objective. One of the popular methods of achieving this goal which has remained extant is Stanislavski's use of the 'Magic If.' This allows them to transcend the confines of realism by asking them what would occur 'if' the circumstances were different, or 'if' the circumstances were to happen to them. Whether on stage or screen, if an actor experiences only internal feelings or only physical actions, then the performance is dead. The reasoning behind this goes back to the union of the psychological and physical which goes mutatis mutandi (hand- in- hand). For an actor to portray a character employing one aspect of the union without the other is to perform incompletely.

\section{The Theatre Challenge}

We engaged some acting students in a debate as to which medium of acting poses a greater challenge to the actor and true to our expectation, majority argued, albeit ignorantly, that stage acting is more challenging than that of the screen. The reason for this somewhat lopsided argument is not far-fetched: they see the rigorous 
trainings, rehearsals, and physical contact with the audience as being very stressful. As far as they are concerned, screen actors just have a field day on set as they do not need to go through the rigors of changing set, costumes in a few minutes while the audience waits.

Acting on stage has a number of challenges that an actor is 'doomed' to face if he must succeed. For the purpose of this paper, we have identified five basic challenges that tend to confront the stage actor.

\section{Rehearsals}

In his article on Acting: Myths, the Reality, Effiong Johnson (2005) identified six conditions that constitute good acting one of which is a thoroughly rehearsed play. According to him, "there could be a good script with good actors under the leading of a very creative director. But if the team does not spend quality time to rehearse the play to the satisfying level of mastery, success may not be attained" (25). This is an aspect of acting that most actors see as challenging in the process of preparing for a particular production, the most boring being the blocking stage.

Actors are expected to go through rigorous rehearsals that span at least four to six weeks for a professional production to be ready for performance during which actors are also expected to memorize their lines and blockings. This is not exactly same with the screen actor who doesn't necessarily need to memorize any line or blocking before the day of recording. He is at liberty to take his lines as much as he can on set as the director can take as many cuts as possible until the actor is able to get the lines correctly. Rehearsals for the stage actor do not end with lines alone. The actor is made to go through series of fitness and concentration exercises that helps maintain a developmental progression for the actor and extends his ability in such a way that he can confidently expect to be effective in a host of acting styles. Jean Sabatine (1995) breaks this sort of training into three parts which he calls the 'Triad.' According to him,

The relationship between the actor's physical, mental and emotional nature forms the organic entity. Therefore, any training must seek to strengthen this organic entity (20).

As a result, his theory of 'triad' is based on a three -stage developmental progression; exercises, explorations and applications. During exercises being the initial stage, the actor is devoted to the fundamental tasks of aligning (internally as well as externally) and conditioning the body. This stage helps the actor to become supple or flexible, confident and precise in movement while eschewing stage fright, awkward gestures and inexpressive immobility.

The second which is the exploration stage is a time when according to Sabatine, "the actor learns everything he can about how the body can be expressive and how the world looks when seen in terms of movement" (22). The application stage is the ability of the actor having gone through the first and second stages will be able to focus his mind, spirit and body on the problem of applying growing awareness and skills to a particular project.

\section{Memorization and Line delivery}

This is an area that poses a great challenge to the actor. This is because it takes a disciplined actor to understand the difference between memorizing or learning lines which we also refer to in colloquial terms as 'jamming the lines'. A number of times I have taken pains to warn my students on the dangers of cramming. Cramming lines distorts the flow of characterization as the actor spends most the time on stage trying not to forget the crammed lines at the expense of the audience. When an actor learns his lines, it becomes easy for characterization to flow. Unfortunately, most directors put actors under so much pressure to do away with their scripts in order to free their hands, a system that has made many actors (especially upcoming ones) to quickly resort to cramming, making them to 'rewrite' the script most often. As an actor, I developed a system of memorizing my lines which I termed as 'shedding skin.' This system of shedding skin can be likened to the life of a snake, it is referred to as moulting by biologists and defined as "the manner in which an animal routinely casts off part of its body either at specific times of the year or at specific points in its life cycle" (Wikipedia).

In the case of the snake, moulting occurs when the old skin is outgrown and the snake will rub against rough surfaces to shed skin. To relate this analogy to the issue of discourse, I liken myself to the snake and the script, my skin. Throughout the period of rehearsals, my script becomes part of my body and I read the lines over and over again. A good actor must not stop reading his script even after he has learned his lines until the production is over. A student confronted me wondering why he shouldn't keep his script at home having 'jammed' his lines. My spontaneous answer was quite revealing as I just replied by asking how old he was and if he was Christian, he told me his age and replied the later in the affirmative and I asked a simple question: you have been reading the Bible for the past twenty three years; you should have read it through by now. How come 
even your father at his age still reads it? He didn't wait for a reply, I think he got my message immediately and left satisfied. This question came as a result of the biblical injunction in Joshua 1:8

Do not let this book of the law depart from your

mouth; meditate on it day and night, so that you

may be careful to do everything written in it.

Then you will be prosperous and successful

(NIV).

This analogy cannot be more apt with regards to my system of shedding skin. This system has worked for me and has given me opportunities to see new meanings in my lines each day as I read through the script. During this process, the lines naturally become part of me and then, having outgrown the skin (script), I shed it. This is further corroborated by Brockett and Ball in their assertion:

Memorization is aided by a few simple procedures.

Because it is impossible to memorize everything at once, the script may be broken into beats and mastered one at each time. In each, the actors must ultimately not only learn their own lines but also memorize the cues (the words or actions of others that precede and trigger their lines) as thoroughly as they memorize specific lines, it is helpful to study the sequence of ideas or shifts in emotion and tone - the overall development of the beat (356).

From the foregoing, it is obvious that the art of memorizing lines is not meant to spontaneous but a process in order for it to culminate into an effective line delivery.

\section{Set/Costume Change}

One of the perks of the role of a screen actor is the access to exotic cars, magnificent houses, designer clothes, to mention a few. This has put a social pressure on most actors who end up living above their means just to maintain the class they exhibited on screen. This is not so for the stage actor who has to play on seemingly different locations set on the same stage. As a result, he has to be fast enough to change from one costume to another to create an illusory passage of time in order not to keep the audience waiting for too long or create a yawning gap during the production. This is more challenging especially when it has to do with flashbacks. A typical example is the flashback scene in Ola Rotimi's Gods are not to Blame when Alaka comes to visit Odewale who tries to explain the circumstances that made him run away from home. Both characters are seated and suddenly Odewale tells his story in a dramatized flashback which involves his fight with the old man whom we eventually get to know as his father. When he returns to the previous scene, the actor is saddled with the task of changing back to the former costume and to also control his breathe after the fight in order to match the calmness of the discussion with Alaka.

An actor is also expected to get used to the set he is to play on. This is usually done on the day of dress and technical rehearsal during which set, light and costume changes will be rehearsed in detail. These sets are usually built with light wood and calico materials to make for easy movement during set change and the actor is expected to be extremely careful in order not to let the set come crashing down during performance, a situation which can be very distracting and embarrassing to the actor and the entire performance.

\section{Performance and Feedback}

The ultimate goal of an actor is to showcase all that he has rehearsed before an audience. The better prepared an actor is, the more confident he will be on the opening night. However, it is rare to see an actor who at one time or the other has not experienced some form of nervousness. Facing the fact that you are nervous before a performance according to Caltagirone "is a major part of taming stage fright." He goes on to assert that for the fact that an actor knows how prepared he is, is a defense against stage fright (9). The stage actor in performance comes face to face with audience and gets a direct feedback for his audience and gets a direct feedback for his performance. This is a fact that most actors on screen are not able to confront. During performances, the actor is expected to be audible and intelligible enough to for the audience to get the flow of the play, he may not be as fortunate as the screen actor who does not need to speak too loud because of the boom microphone which will amplify his voice. On stage, the actor is also at the mercy of the audience who can become very restive if they are bored as a result of poor performance.

Another aspect of performance that tasks the actor's ability has to play a role repeatedly during multiple runs of the same production. As Brockett and Ball put it:

Long runs create special dangers because the actors may begin to perform mechanically because of over familiarity with their roles. The best guards against such letdowns 
are concentration and reminders that each performance is the first for this particular audience (358).

From the foregoing, actors apart from being too familiar with their roles tend to get bored with same routine as long as the production will last.

\section{Remuneration}

The cliché that says 'the show must go on' is common among artistes and has come to be the slogan of members of Actors Guild of Nigeria (AGN). The slogan means that we should practice arts for art's sake not minding the financial fulfillment in remuneration, a dictum I consider to be quite unrealistic. In protest, some artistes who share the same view with me have tried to counter the slogan by insisting that the show must not go on but 'the artiste must survive.' Live theatre productions in Nigeria especially have suffered patronage and corporate sponsorship, a situation that has driven actors to look for alternative means of livelihood and kept those who are not fortunate enough to become beggarly. A few corporate bodies like Shell, Nigeria Liquefied Natural Gas (NLNG), INTEL and a few others have always blazed the trail in their support of live theatre performances for their club members. The fact remains that these productions are seasonal and too few for the teaming population in the industry.

\section{Facing the Camera}

Just as we study and practice different techniques and styles of acting to make good stage performances, the screen actor also needs to develop some skills that are unique to acting for the camera. An actor has to be familiar with camera techniques in order to forestall a poor performance. Not a few actors think that movement on stage is calculated to make for balance and composition, but that may not totally true. Actors are also blocked on the film set and they are expected to move within the frame of the shot at that particular time, maintain eye levels and continuity of character from shot to shot. According to Caltagirone,

The use of the body is important on camera as well as on stage. In fact, in a film it may be more critical. The camera is unforgiving. You may have heard of actors gaining fifty pounds for a particular role. An actor will do this in order to look the part he or she is playing better. Because the camera may often show the actor's close-up, it is even more important to have the body look right for the part (275-76).

There also seem to be a psychological position to this in the sense that viewers of live theatre performances tend to feel that stage actors exert a lot of energy because they witness the art of line delivery, set and costume change on the spot. On the other hand, watching the actor on screen from the comfort of one's home tends to give the viewer sense of ease as the actions are shown having been edited in the absence of the viewer. This creates some form of choice for the would-be actor who would then imagine the screen experience as the preferable option.

In order to achieve a comparative analytical study, I have also identified five challenges that confront the screen actor.

\section{Familiarity with other actors}

Unlike the stage actor who is 'doomed' to rehearse a play for several weeks or even months, the screen actor may not need to go through what many may term as the stress of rehearsals. However, while the rehearsal period affords the actor the opportunity to get familiar with fellow actors, the screen actor often gets to meet fellow actors for the first time on set. According to Giannetti (1996):

Unlike the stage player, the film actor doesn't have to

create an intimate rapport with other performers:

Sometimes they haven't even met until they arrive on the set or on location. Actors occasionally don't know their lines: this is remedied by having a prompter on the set, or by writing the lines on a blackboard off frame where the actor can read them (248).

As a result, most upcoming actors have been known to be dwarfed on the set by the stars that see this as an opportunity to shine. In such cases, you find the actor having to go through many retakes as a result of this nervousness. 


\section{Continuity}

This can be said to be the greatest technical challenge that a screen actor faces. Whilst the stage play has to run chronologically, recording for a film is done for logistic convenience. As Caltagirone puts it:

When a director sits with a screenplay, he or she does not decide to start filming at the beginning and go straight to the end. For example, if there are eight scenes where a character is on a farm, these eight scenes will all be shot together, even though they appear at different times in the movie (279).

Giannetti also corroborates this view:

The shooting schedule of a movie is determined by economic considerations. Thus, the shooting of various sequences isn't always artistically logical. An actor may be required to perform the climactic scene first and lowkeyed exposition shots later. The screen actor, then, doesn't 'build' emotionally as the stage actor must. The film player must be capable of an intense degree of concentration- turning emotions on and off for very short periods of time (247).

During such occasions, the actor is faced with the task of maintaining continuity in character and delivery. Most times, when we observe a certain epileptic flow in the character of an actor, it probably means that such an actor has not been able to master the art of character continuity. Actors who are not conscious of this are left at the mercy of the continuity writers who may not also be able to remember the all the flow of events, a mistake which can become very costly at the point of editing.

\section{Location and Shooting}

We carefully chose this point for the sake of those who erroneously feel that the stage art is too rigorous an experience for the actor. Films unlike stage plays are recorded with almost every sense of actuality. Most stories or scenes that would have otherwise been reported in a stage play will have to be shot in a movie. Film requires the actor to go on location to some very distant places, away from family and friends for some time. At times, as in the case of the Nigerian experience, very remote areas that may not have good water and electricity supply thereby keeping the actor in a most uncomfortable state. We have had the experience through my participation in the adaptation of Elechi Amadi's novel, Concubine to film and also directed the stage adaptation of same novel. While I comfortably rehearsed and staged the play in a theatre with most of the scenes reported, we had to travel all the way to a remote village in Abakpa-nike, Enugu state for the shooting of Concubine in order to get a semblance of Omuigwe, Omuokachi and Chiorlu villages as mentioned in the script. War scenes in movies can also be very energy sapping for actors as they have to do a lot of retakes from several angles according to how the director has decided to interpret the script. Actors are known to have sustained fatal injuries as a result of running through unknown forests during recording. Caltagirone also posits:

The long grueling hours of filming place a physical demand on an actor as well. If you are performing on stage, you have two hours of performance. If you do a matinee and an evening performance, you may have four hours on stage. But with film work, you may spend long hours on set day after day while the director is shooting the scenes you are in (279).

As a result of the above stated, actors sometimes are made to stand under the scorching sun to record scenes that may take several hours of takes and retakes or stay out in the cold night for scene that are to be shot at night. Actors have most times been known to have encountered robbers and other ugly incidents on their way back from location at very ungodly hours.

\section{Performance and Feedback}

It will be very erroneous to think that the screen actor does not have to battle with the challenges of fright and feedback. In fact, screen actors are confronted with feedbacks both at short and long terms. The short term feedback occurs on set during recording. A look at the opening and end credits in a movie will go a long way to help us imagine the number of persons behind the camera during recording sessions. This is what I call the primary audience of the screen actor. At this point, the actor can also become nervous in his performance which often makes the director and other crew members get worked up. Many screen actors have lost roles due 
the fact that they are unable to deliver lines appropriately during shooting while some others get applause on set after recording some sensitive scenes of confrontation, romance, emotion etc. As Giannetti puts it:

A film actor is expected to play even the most intimate scenes with dozens of technicians on the set, working or observing. The actor must seem totally at ease, even thought the lights are unbearably hot and his or her running makeup has to be corrected between shots. Because the camera distorts, actors are required to perform some scenes unnaturally. In an embrace, for example, lovers can't really look at each other in the eyes or they will appear cross-eyed on the screen. Much of the time the performer has no idea what he or she is doing, or where a shot might appear in the finished film, if indeed it appears at all, for many an actor's performance has been left on the cutting room floor. In short, the discontinuity of time and space in cinema places the performer almost totally in the hands of the director (249).

The end consumers are then the secondary audience who watch these films after they have gone through the process of editing and fine tuning. I call them secondary because they were not privileged to see the film in its raw state with all the mistakes leading to several retakes. The feedback becoming more taunting if the movie unfortunately turns out to be a bad one. This is in direct contrast with the belief that in film acting there really is no feedback until the finished product is put out and hailed as a good work.

Unlike the live theatre performance whose memory can fade away with time, these movies are documented and in the hand $\mathrm{s}$ and houses of the audience and they could always replay it to relive either negative memories due to bad performance or positive memories due to a fantastic outing. Such outstanding performances tend to change the names of these actors to their character names. A good example of such an actor is Sam Dede who at first sight in public is quickly referred to as Issakaba.

\section{Offset and Social Life}

The glamour associated with most roles in the movies has forced most actors to live a false life outside location. While some actors are paid handsomely for their roles, most actors still have to go home with little or nothing after taking part in a movie. As a result, these persons go out of their way to update their wardrobe in order to look good and pay journalists to write stories about them with money often from other sources. Some actors are known to go as far as lobbying producers and directors for roles that will project them into lime light without artiste fees or in exchange for sex. For this reason, we see most screen actors living above their means just to maintain a particular class or status. It however, becomes a strenuous job to live up to the way one looks on screen.

\section{Summary}

For the stage and screen actor, the answer lies in the basis of all acting: truth. The theatre, just like film, is about depicting human truth within the circumstances of the script. A stylized, or period piece aside, the stage actor seeks to first discover natural human truth and then find the appropriate tools of expression to bring that truth to an audience. Because of the distance between the stage and the audience, an actor can learn habits of expression that demonstrate an emotion that is not truly grounded within the body. On the other hand, the camera puts the actor knee to knee with the audience. As this image implies, there is no excuse for accentuating an emotion or adding gestures of physical expression. In fact, these additions tend to come when the actor doesn't have the truth of experience within his body. He is virtually unable to hide, so the truth of his experience (or lack thereof) is evident. This is so because same instincts to demonstrate show up as a result of the actor's inability to ground the truth of experience in his body.

\section{Works Cited}

[1] Brockett, Oscar and Ball, Robert. The Essential Theatre. Wadsworth: Canada. 2004

[2] Caltagirone, Dennis. Theatre Arts: The Dynamics of Acting. NTC Publishing Group; Chicago. 1997.

[3] Giannetti, Louis. Understanding Movies. Simon \& Schuster: New Jersey. 1996

[4] Isbell, Tom. Lessons: The craft of Acting. Meriwether Publishing: Colorado. 2006

[5] Johnson, Effiong (ed.). The Art of Acting: A Student Friendly Anthology. Concept Publications: Lagos. 2005.

[6] -------------- Acting: the myths, the reality In Effiong Johnson (ed.) The Art of Acting: A Student Friendly Anthology. Concept publications: Lagos. Pp 13-34. 2005.

[7] Mamer, Bruce. Film Production Technique: Creating the Accomplished Image. Wadsworth: Toronto. 2003.

[8] Sabatine, Jean. Movement Training for the Stage and Screen: The Organic Connection between Mind, Spirit and Body. Backstage Books: New York. 1995 
[9] Tornqvist, Egil. Between Stage and Screen: Ingmar Bergman Directs. Amsterdam University Press: Amsterdam. 1995.

\section{About the Contributors}

Ovunda Ihunwo schooled at the University of Port Harcourt where he has successfully graduated with a Certificate in Theatre Arts (C.T.A), Bachelor of Arts (B.A. Theatre Arts) and a Masters Degree in Film Studies with special interest in the study of Auteur Theory and its application to the Nigerian Video Film Industry. He is an actor, Singer, Dancer and currently the National Vice President of Actors Guild of Nigeria (AGN). He is currently a lecturer in the Department of Theatre Arts, University of Port Harcourt, Nigeria.

Sam Dede holds the B.A, and M.A. degrees in Theatre Arts from the Universities of Benin and Port Harcourt respectively. His areas of interest include acting for stage and screen. He is one of Nollywood's most popular actors as he has featured in over a hundred movies. He is a lecturer in the Department of Theatre Arts of the University of Port Harcourt and is currently the Director-General, Rivers State Tourism Development Agency, Nigeria. 